
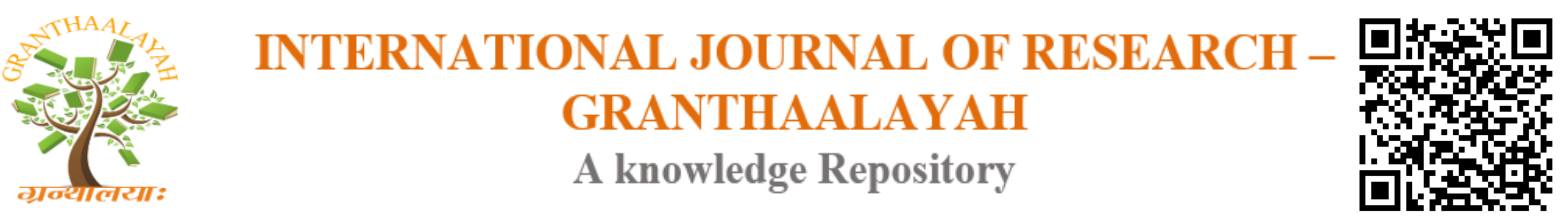

Social

\title{
PERFORMANCE ANXIETY AND SLEEP PROBLEMS AS PREDICTORS OF ACADEMIC ACHIEVEMENT
}

\author{
Namra Shahzadi ${ }^{1}$, Misbah Arshad ${ }^{2}$ \\ ${ }^{1,2}$ Department of Psychology, University Of Gujrat, Punjab, Pakistan
}

\begin{abstract}
The present study investigated performance anxiety and sleep problems as predictors of academic achievement among a convenience sample of 100 university students (Male = 43, Female $=57$ ).

Method: The participants, aged 18 to 25 years, were selected from three different departments of University of Gujrat. Hamilton Anxiety Scale (Hamilton, 1959) and Pre Sleep Arousal Scale (Nicassio, Mendlowitz, Fussell, \& Petras, 1989) were individually administered to the participants in their respective departments. Academic achievement was measured in terms of GPA of previous semester of each respondent.

Results: The Cronbach Alphas for both the scales for the present sample fell in acceptable range $(\alpha=0.84-0.87)$. Linear regression analyses indicated that performance anxiety significantly predicted ( $\mathrm{p}<.01, \mathrm{p}<.001)$ of low academic achievement among university students. It was also identified that the higher level of performance anxiety was also a strong predictor $(\mathrm{p}<.0 .001)$ of sleep problems among students.

Conclusions: Discussion includes implications for future research and practices with reference to Pakistani culture.

Keywords: Performance Anxiety; Sleep Problems; Academic Achievement; University Students.

Cite This Article: Namra Shahzadi, and Misbah Arshad. (2017). "PERFORMANCE ANXIETY AND SLEEP PROBLEMS AS PREDICTORS OF ACADEMIC ACHIEVEMENT." International Journal of Research - Granthaalayah, 5(7), 399-407. https://doi.org/10.29121/granthaalayah.v5.i7.2017.2146.
\end{abstract}

\section{Introduction}

Anxiety plays important role in over life positively as well as negatively. We can better performed and respond to any tasks assign to us when we take it seriously and anxious about their outcome. According to Spielberger (1983) "anxiety is a psychological and physical response to treat a self-concept characterized by subjective, consciously perceived feelings of tension". 
Performance anxiety (PA) is maybe as old as artistic performance itself, psychological research on it started only about some decades ago. The main characteristics are (1) irrational, perfectionist, or catastrophic cognitions (2) physiological symptoms like trembling, hyperventilation, or palpitation and (3) behavioral characteristics like the avoidance of performances and auditions (Pilcher et. al, 1997).

All most all kind of population child, adult and old or professional and nonprofessional people reported different kind problems regarding anxiousness in their daily performing tasks. But the students are the most vulnerable population who faced different types of anxiety and especially performance anxiety in their academic career. University atmosphere has worldwide access to increase level of study and performance anxiety among students. University students have to face such kind of pressure and anxiety, especially when they are going to performing in class or in examination. Difficult subjects, new classmates, adjustment issues, educational distress, and having good company and maintaining relationship with friends boost level of the anxiety among students (Leroy, 1980).

According to Leta (2001) anxiety disorders are rising among students and it interrupted badly with students' performance day by day. Many students have to face different kind of problems associated with anxiety symptoms for example anxiousness or feeling low during their study career such as anxiety related to examinations, performance, social and family anxiety. However, most of students would lack the concentration of study because of exam anxiety, social anxiety, mathematic anxiety, and many anxiety sources.

Feeling discomfort and anxious in the classroom does not enhance learning of any kind. The anxiety's psychological symptoms among students include feeling nervous before a study class, panicking, going blank during a test, feeling helpless while doing assignments, or lack of interest of subjects difficult whereas the physiological symptoms include sweaty palms, racing heartbeat, or an upset stomach(Pilcher et. al, 1997).

Students who faced performance anxiety are reported with low academic achievement or underachievement. It is stated that achievement and performance anxiety has major role in the career development of the students. Academic achievement is a term used to describe the rating of a student following an examination.

"Achievement is define as a result of emotional conflict between striving for success and avoiding failure" (Covington, 2004; Heafner,2004). If a student does not feel afraid he will not be able to do work harder to achieve the goal (Seligman, 200). Academic anxiety is a kind of state anxiety which relates to the impending danger from the environment of the academic institutions including teachers, certain subject's like Mathematics, English etc (RohenMeetei, 2012).

University students are at that point of academic career where they are about to enter the professional and practical life. This period of study is very critical and important not only for their career but also for the development of their personality and abilities (Gelder\& Harrison, 2010). At this stage of studies students have to face many problems, decline in performance and 
the achievement of the preferred goals. Sleep deprivation, social activities, work related responsibilities academic and some other factors turn the heads of the students (Leroy, 1980).

Sleep is as essential for human being as food and water. According to Durand and Barlow (2003) sleep is a natural periodic state of rest for the mind and body. In sleep state eyes usually close and consciousness is completely or partially lost, so that person's bodily movement and responsiveness to external stimuli decreases. Sleep occupies almost a third of life and thus is an important aspect of human life. It is as essential for physical health as for mental growth and stability. Deprivation of sleep not only weakens physical and mental functions but also could causes mental problems and lowers work productivity (Ban \& Lee, 2001).

Sleep problems have been associated with deficits in attention, concentration and overall performance. It is also reported that unhealthy sleep patterns affect memory, health, coping strategies and social relationships. Professionals, people with multiple psychological problems and especially students are the most vulnerable for having the problem of sleep disturbances (Comer, 2004).

Many studies have being carried out to identify the sleep problems among the students. Buboltz, Brown and Soper (2001) carried out a preliminary study to assess the sleep habits and sleep patterns of college students. It was reported through results that most of the students from Southern university exhibited some form of sleep problems and female ratio was higher than male. Thus it was taking highly serious in many schools, college and especially in universities that students must provide facilities regarding career guidance and counseling.

The empirical evidence highlights the possible link between performance anxiety, academic achievement and sleep problems in university students. So for this reason currently study was designed to explore the impact of performance anxiety and sleep disturbance on academic achievement experienced by university students.

\section{Materials and Methods}

A thorough literature review has shown that sleep problems and performance anxiety have significant effect on student's academic achievement. The aim of the study was finding out the relationship between performance anxiety and sleep problems among university students.

\section{Sample}

Randomly selected sample of 100 students (Male=50, Female=50) age range between 18 to 24 years was selected in this research on the basis of their convenient. Students were randomly selected from psychology, sociology and Business department of University of Gujrat, Hafiz Hayat Campus. The academic qualification of the sample was BS (Hon) $2^{\text {nd }}$ and $8^{\text {th }}$ semester.

\section{Sampling Procedure}

Stratified random sampling technique was used to select the students of $2^{\text {nd }}$ and $8^{\text {th }}$ semesters from university of Gujarat. By using stratified sampling target population selected from university was further divided into strata by selecting different departments including $2^{\text {nd }}$ and $8^{\text {th }}$ 
semester of BS Hons. These strata's were also divided in to sub strata of male and female students.

\section{Instruments}

The following scales were used in this phase:

1) Demographic Questionnaire

2) Hamilton Anxiety Scale (Hamilton, 1959)

3) Pre Sleep Arousal Scale (Nicassio, Mendlowitz, Fussell, \& Petras,1989)

4) Grade Point Average (GPA)

\section{Procedure}

First of all permission was taken from the different head of departments and also assured that all information will be used for research purpose only. Bs Hons students of $2^{\text {nd }}$ and $8^{\text {th }}$ semester were approached in their classes. Information regarding purpose of the study, time required for administration was given to the participants. Consents from research participants were taken and confidentiality was assured to them. After that each participant was provided with complete protocol consisted of Hamilton anxiety scale, Pre sleep Arousal Scale and GPA. Verbal instructions were given to all the students and they were asked to read complete instructions on the top of the scale and rated each item. On the average participants took 25 minutes for administration. Group administration was done for complete procedure. Students were also encouraged to ask questions regarding the research.

\section{Results}

\section{Psychometric Properties of Scales}

The method of Cronbach's alpha reliability was used to measure the internal consistency of the scale.

Table 1: Reliability Statistics of Hamilton Anxiety Scale

\begin{tabular}{ll}
\hline Cronbach's Alpha & Number of items \\
\hline .87 & 14 \\
\hline
\end{tabular}

Table 1 indicates that the internal consistency among the 14 items of Hamilton Anxiety Scale. Result indicated this scale has .87 Cronbach Alpha which has highly significant reliability to use this scale for student population.

Table 2: Total Items Corrected Correlation of Use of Hamilton Anxiety Scale

\begin{tabular}{lllll}
\hline Items & $\begin{array}{l}\text { Scale Mean if } \\
\text { Item Deleted }\end{array}$ & $\begin{array}{l}\text { Scale Variance } \\
\text { if Item Deleted }\end{array}$ & $\begin{array}{l}\text { Corrected Item- } \\
\text { Total } \\
\text { Correlation }\end{array}$ & $\begin{array}{l}\text { Cronbach's } \\
\text { Alpha if Item } \\
\text { Deleted }\end{array}$ \\
\hline Anxious mood & 20.16 & 104.52 & .43 & .87 \\
Fear & 20.60 & 100.93 & .49 & .87 \\
Respiratory & 20.40 & 97.21 & .62 & .86 \\
symptoms & & & & \\
\hline
\end{tabular}


Table 5 indicates total item corrected correlation. The scale of Hamilton Anxiety Scale consists of 14 items. Only three items are given in the table, item corrected correlation for rest of all items is given in appendices. Results indicated that all items have significant inter item corrected correlation $\mathrm{r}(98), \mathrm{r}>.195$.

Table 3: Reliability Statistics of Pre Sleep Arousal Scale

\begin{tabular}{ll}
\hline Cronbach's Alpha & Number of items \\
\hline .84 & 16 \\
\hline
\end{tabular}

Table 3 indicates that the internal consistency among the 16 items of Pre Sleep Arousal Scale. Result indicated this scale has .84 Cronbach Alpha which has highly significant reliability to use this scale for student population.

Table 4: Total Items Corrected Correlation of Pre Sleep Arousal Scale

\begin{tabular}{lllll}
\hline Items & $\begin{array}{l}\text { Scale Mean if } \\
\text { Item Deleted }\end{array}$ & $\begin{array}{l}\text { Scale Variance } \\
\text { if Item Deleted }\end{array}$ & $\begin{array}{l}\text { Corrected Item- } \\
\text { Total } \\
\text { Correlation }\end{array}$ & $\begin{array}{l}\text { Cronbach's } \\
\text { Alpha if Item } \\
\text { Deleted }\end{array}$ \\
\hline $\begin{array}{l}\text { Heart racing } \\
\text { Review }\end{array}$ & 36.24 & 105.53 & .45 & .83 \\
events & 35.70 & 104.35 & .43 & .83 \\
Mentally alert & 35.48 & 106.83 & .30 & .84 \\
\hline
\end{tabular}

Table 4 indicates total item corrected correlation. The Pre Sleep Arousal Scale of 16 items. Only three items are given in the table, results indicate that 16 items have significant inter item corrected correlation $\mathrm{r}(98), \mathrm{r}>.195$. which indicated that this scale is reliable and valid.

\section{Hypothesis 1:}

There is positive correlation between performance anxiety and sleep problems among university students.

\section{Hypothesis 2:}

There is negative correlation between performance anxiety and academic achievement.

Table 5: Correlation Metrics of Scales of University Students (N =100)

\begin{tabular}{llll}
\hline & Total PSAS & Total Anxiety & GPA of students \\
\hline Total PSAS & - & $.533^{*}$ & .321 \\
Total Anxiety & - & - & .093 \\
GPA of students & - & - & - \\
Mean & 38.24 & 21.71 & 3.02 \\
SD & 10.79 & 10.74 & .48 \\
\hline
\end{tabular}

$* P<.001$

Table 5 shows correlation metrics of GPA, total pre sleep arousal scale and total anxiety scale. The $\mathrm{p}$ value $(\mathrm{p}<.001)$ shows highly significant relationship between performance anxiety and sleep problems. Table also shows that academic achievement of students is not significantly correlated with anxiety and sleep problems among university students. Mean and SD scores also 
indicated highly significant differences on anxiety sleep problems and GPA of university students.

\section{Hypothesis 3:}

Students experiencing more performance anxiety will have low academic achievement.

Linear regression analysis was carried out to find out the relationship between performance anxiety and academic achievement where anxiety is a dependent variable and academic achievement is independent variable.

Table 6: Linear Regression Analysis, Enter Method Predicting Performance Anxiety with Academic Achievement in University Students $(\mathrm{N}=100)$

\begin{tabular}{llllc}
\hline & \multicolumn{5}{c}{ GPA } \\
\hline Factors & $B$ & SEB & $\beta$ & $t$ \\
\hline Somatic & .01 & .00 & .19 & 1.5 \\
Psychic & .00 & .01 & .01 & .92 \\
Total Anxiety & .008 & .00 & .16 & .93 \\
$\mathrm{R}^{2} .16$ & & & & \\
$\triangle \mathrm{R}$ & .02 & & &
\end{tabular}

Table 6 shows regression analysis of academic achievement, anxiety and two factors of Hamilton Anxiety Scale. Beta value .19 and $p$ value (<.001) shows that somatic problems are significant predictor for poor academic performance among students. Furthermore the beta and $p$ value $(<.001)$ of psychic symptoms also shows significant results which revealed that psychic symptoms are predictor for low academic achievement. Overall total Anxiety scores shows that $p$ value (<.001) and $\beta$ value in the table indicates that performance anxiety in strongly predictor for low academic achievement among university students. The value of $\mathrm{R}^{2}$ shows $16 \%$ of variation in performance anxiety. This means $84 \%$ of variation in poor academic achievement is influenced by other factors.

\section{Hypothesis 4:}

Higher level of performance anxiety will lead to higher level of sleep disturbances among university students.

Linear regression analysis was carried out to find out the relationship between anxiety and sleep problems where sleep problems are dependent variable and anxiety is independent variable.

Table 7: Linear Regression Analysis, Enter Method Predicting Anxiety with Sleep Problems in University Students $(\mathrm{N}=100)$

\begin{tabular}{llllc}
\hline \multicolumn{5}{c}{ Sleep problem } \\
\hline Factors & $B$ & SEB & $\beta$ & $t$ \\
\hline Total Anxiety & .53 & .08 & .53 & 6.23 \\
$\mathrm{R}^{2} .31$ & & & & \\
$\triangle \mathrm{R}$ & .55 & & & \\
\hline
\end{tabular}

$p>.0 .001$ 
Table 7 shows linear regression analysis of total anxiety and total pre sleep anxiety scale. Beta value .53 and $p$ value (<.001) shows that anxiety is significant predictor for sleep problems among university students. The value of $\mathrm{R}^{2}$ shows $31 \%$ of variation in anxiety. This means $69 \%$ of variation in sleep problems is influenced by other factors.

\section{Hypothesis 5:}

Higher level of sleep problems will lead to lower level of academic achievement among university students.

To test this hypothesis linear regression analysis was applied to find out the relationship between the levels of sleep problems and lower academic achievement where sleep problems are an independent variable and GPA of students is dependent variable.

Table 13: Linear Regression Analysis, Enter Method Predicting Sleep Problems with GPAof University Students (N=600)

\begin{tabular}{|c|c|c|c|c|}
\hline \multicolumn{5}{|l|}{ GPA } \\
\hline Factors & $B$ & $S E B$ & $\beta$ & $t$ \\
\hline Somatic Arousal & .00 & .01 & .10 & .83 \\
\hline Cognitive Arousal & .00 & .09 & .01 & .12 \\
\hline Total PSAS & .00 & .005 & .10 & .99 \\
\hline $\mathrm{R}^{2}$ & & .28 & & \\
\hline$\triangle R$ & & .53 & & \\
\hline
\end{tabular}

Table 13 shows linear regression analysis of GPA, total and subscale of pre sleep arousal scale. The $\mathrm{p}$ value $(\mathrm{p}<.001)$ shows highly significant relationship between sleep problems and lower academic achievement. It also depicts that high level of sleep problems is predictor of low academic achievement among university students. Table also shows that academic achievements of students are linked with both somatic arousal and cognitive arousal. The value of $\mathrm{R}^{2}$ shows that anxiety has accounted for $28 \%$ of variation. This means $72 \%$ of variation is influenced by other factors than sleep problems.

\section{Discussion}

Anxiety is a common feature of many societies which not only affecting the performance of children and adults but also the older people as well. Having performing anxiety any task reduces energy, increase alertness, impairs judgment and has significantly negative affects on our health and moods (Davison \& Neal, 2009). Students are the most vulnerable population who has to face mostly challenging works during their academic career. Assignments, quiz, presentation and examination creates different kind of psychological distress and different types of anxiety among students.

Current study was aimed at exploring the relationship between performance anxiety and academic achievement and results indicated that high level performance anxiety is strongly enough to predict poor academic achievement among university students. Researches also indicated that high level anxiety had negative impact on academic achievement of university 
students. Students always reported that due to experiencing performance anxiety before and during presentations, quiz and examination they could not perform up to the mark. Which is the most common and treating cause for lower academic performance, mental abilities and failure (Nadeem, Ali, Maqbool\&Zaidi , (2012) Mahmood (2010) and Kazmi, 2013).

Second research hypothesis was to find out that high levels of performance anxiety will leads to high level of sleep problems among university students. It was revealed that anxiety was significantly higher predictor for sleep problems among students. During the academic years students suffer from many difficulties and challenges, moreover their teachers, family members always expect good performance at every stage. Huberty (2001) also find out highly significant relationship between high level of anxiety and high level of sleep problems. Stress and high expectations sometimes creates different kind of anxiety such as social, performance, exam among students. It is not unusual for students to experience excess of anxiety in face of external demands. This anxiety according to results of current study leads to sleep disturbances.

Relationship between sleep problems and academic achievement was also identified. It was explored that sleep problems were significantly high predictor for lower academic achievement among students. It was also identify that students experience same level of somatic and cognitive arousal which is reported to have significant affect on their poor performance. Insufficient sleep create many kind of problems and students mostly reported the somatic arousal symptoms like heat pounding, have stomach upset and tense feelings in muscles they cannot perform up to the mark and leave that task incomplete.

It was also explored that cognitive arousal also significantly higher predictor for lower academic achievement among students. It is revealed through results that whenever students having negative thoughts, being mentally alert all the time being and can distracted easily they cannot concentrate on their actual work. Due to lack of such attention and concentration they cannot meet the deadlines or perform well which develops emotional and physical exhaustion and distorted self-image. At the end students cannot be able to put his or her best effort to achieve his/her targets and faced poor academic performance or results.

According to Pakistani culture male population have to face more burden of work and high expectations from their families as compare to female that lead to develop more anxiousness. Male students have to face strict competition not only with same gender but also with females they have to work hard and study overnight which causes disturbance not only in their sleep pattern but also develop different type of phobia and anxiety.

University students in Pakistan are now following semester system due to which students experience different problems that are characteristics of problems like adjustment issues, poor time management, performance anxiety etc. current study also attempts to explore the gender differences among first year and last year students in terms of experiencing anxiety and the results showed some interesting facts. First year students were found to be experiencing more performance anxiety than the last year students. In current educational system, when a student enter the university he/she have to face many issues such as adjustment problems, separation anxiety, low self-esteem, fear of performance and evaluation than the last year students. 


\section{Conclusion}

On the basis of the findings of this study, it can be concluded that fairly high number of students are experiencing performance anxiety and this area needs serious attention. It can also be concluded that the relationship of performance anxiety, academic achievement and sleep problems is very strong and anxiety can lead to sleep problems and poor academic achievement. Lastly, the study provides counselors, researchers and teachers with reliable and valid tools for exploring anxiety and sleep problems in university population.

\section{References}

[1] Ban, J. D., \& Lee, J. T. Sleep duration, subjective sleep disturbance and associated factors among university students in Korea. The Korea Academy of Medical Science, 16, 2001, 475-480.

[2] Buboltz, C. W., Brown, F., \&Sope, B. Sleep habits and patterns of college students: A preliminary study. Journal of American College Health, 50, 2001, 131-135.

[3] Comer, R. J. Abnormal Psychology (8th ed).U.S.A: Freeman\& Company. 2004.

[4] Davison,G.C.,\& Neale,J. M. Abnormal Psychology (11thed).New York: The Guilford press. 2009.

[5] Durand, V. M. \& Barlow, D. H. Essentials of abnormal psychology (3rd ed.). Belmont, CA: Wadsworth-Thomson Learning. 2003.

[6] Hamilton, M.. Diagnosis and rating of anxiety. British Journal of Psychiatry,3, 1969. 76-79.

[7] Huberty, J. T. Anxiety and anxiety disorder in children: Information for parents. National Association of School Psychologist, 1, 2001. 1-4.

[8] Lowry, M., Dean, K., \&Manders, K. The link between sleep quality and academic performance for college student. Undergraduate Journal of Psychology, 3, 2010. 16-19.

[9] Nadeem, M. Ali., A, Maqbool, S., \& Zaidi, U. S. Impact of anxiety on the academic achievement of students having different mental abilities at university level in Bahawalpur. International online Journal of Educational Science, 43, 2012. 519-528.

[10] Nicassio, M. P., Mendlowitz, R. D., Fussell, J. J., \&Petras, L. Thephenomenology of the presleep state: The development of the pre-sleep arousalscale. Behavioral Research and Therapy, 23, 1985. 263-271.

[11] Spiegler, M.D., Guevremount,D.C. Contemporary Behavior Therapy(5thed).USA: Wadsworth Cengage Learning. 2003.

*Corresponding author.

E-mail address: Shahzadi@uog.edu.pk 